\title{
LÍNEAS ESENCIALES DE LA EXHORTACIÓN APOSTÓLICA POSTSINODAL "CHRISTUS VIVIT» DEL PAPA FRANCISCO
}

DOI: https://doi.org/10.52039/seminarios.v65i226.21

DOMINGO MONTSALVE

\section{PREMISA}

La lectura de Christus vivit, verdadero documento orientador del papa Francisco, reclama por su extensión el esfuerzo de subrayar sus líneas más importantes, con el fin de superar la tentación de hacer de él una lectura superficial.

Muy claro quiere dejar su autor desde el inicio que el trabajo llevado a cabo por los jóvenes durante el Sínodo le ha guiado a la hora de realizar este documento. Así, en el número 4 de la exhortación dice el Papa: «Me he dejado inspirar por la riqueza de las reflexiones y diálogos del Sínodo... He tratado de asumir en la redacción de esta carta las propuestas que me parecieron más significativas. De este modo mi palabra estará cargada de miles de voces de creyentes de todo el mundo que hicieron llegar sus opiniones al Sínodo. Incluso los jóvenes no creyentes, que quisieron participar con sus reflexiones, han propuesto cuestiones que me plantearon nuevas preguntas».

Fiel a este objetivo, la exhortación recorre un camino, poniendo las pisadas en las huellas y resaltando lo más importante de las reflexiones. Esas que invitan a un acercamiento al mundo de los jóvenes que, si nunca ha reproducido completamente el de sus mayores, en nuestros días se encuentra aún más lejos y aparentemente ha interpuesto una distancia insalvable, porque no conocemos a fondo cuáles son sus verdaderas inquietudes, sus valores y sus dificultades para proponerlos en una sociedad de la «información masiva», que no de la «comunicación». Esto nos obliga a conocer el lenguaje (no sólo de palabras, sino también de gestos) que nos pone en contacto con la semántica de esos sonidos que conforman palabras antiguas, pero con un significado ciertamente nuevo. Subrayar los ejes sobre los que se asienta este documento dedicado a «los jóvenes y a todo el pueblo de Dios». 
Esta dedicatoria es toda una propuesta de intenciones; quiere que se impliquen tanto los jóvenes como las comunidades de referencia; no en vano, los jóvenes han tenido importancia capital en el desarrollo de la historia de la salvación. Este es el motivo por la cual nos presenta la acción de los jóvenes en la Biblia y cómo Dios se ha servido de su frescura para encargarles misiones importantes en favor de su pueblo: Gedeón, Samuel, David y Salomón, Rut... son todos ellos una presencia joven que, además, les lleva a cumplir la misión desde el reconocimiento de su debilidad: Gedeón se esconde de los que dominan a su pueblo; Samuel es un niño que cree oír una voz que desconoce, y por ello necesita orientación; lo mismo la visión de David, al que sus padres no tienen en cuenta (porque Dios no mira las apariencias, sino el corazón); Salomón y las mañas de su madre para que sea el sucesor de David. La generosidad de Rut. Los jóvenes no ocultan la realidad, la asumen tal cual es, y este rasgo da confianza al Señor, porque quiere que, con su fuerza, nos arriesguemos a la tarea. Esa evangelización que necesita hoy ser renovada desde el ser y vivir de los jóvenes, con mirada de futuro, asumiendo la realidad, pero sin que el peligro los detenga. $Y$ todos ellos culminan en la persona siempre joven de Jesús de Nazaret, él es el eternamente joven. Con él se nos pide eliminar la levadura vieja ( 1 Cor 5,7$)$ y que abramos el horizonte de la vida. Porque es necesario lanzarse valientes al futuro, mientras se tiene la energía, porque: «Si has perdido el vigor interior, los sueños, la esperanza y la generosidad, ante ti se presenta Jesús como se presentó ante el hijo muerto de la viuda, y con toda su potencia de Resucitado el Señor te exhorta: 'Joven, a ti te digo, ¡levántate!' (Lc 7, 14)».

He aquí las cuatro ideas que deben permanecer en nosotros para hacer eficaz la exhortación Christus vivit. Aparte de otras consideraciones, queremos subrayar estos aspectos importantes a tener en cuenta tanto por los jóvenes como por el pueblo de Dios:

1) Dios es Amor: te ama, le importas, su amor lo define.

2) Este amor está por encima de tus pecados; sin merecerlo, él te regala la salvación, te abre una perspectiva nueva, te ofrece el tesoro de la verdadera riqueza, como hace con el rico que prefiere la seguridad de su dinero a la oferta de tener un tesoro en los cielos.

3) Cristo está vivo, ha resucitado.

4) Es Espíritu y da vida. Y, si Cristo ha resucitado y el Espíritu da vida, no tienes que temer ni al pecado ni a ser un ser insignificante, porque, entregado a su amor, no tendrás más remedio que comunicarlo a los demás. El mal no tiene la última palabra. 


\section{DIOS ES AMOR}

\section{Dios te ama}

En el número 112 de la Exhortación, tras decir a los jóvenes que son el ahora de Dios, quiere comunicarles, hacerles conscientes de que Dios ama a cada uno personalmente, no como un individuo más de la especie, sino de manera personal y singular. En el siguiente número hace alusión a la posibilidad de que no haya existido una buena experiencia con el rol de su padre, porque era autoritario o no reunía las cualidades que él necesitó que lo adornaran. Sin embargo, anima a arrojarse en manos del Padre divino, Él es amor y ternura. Citando al profeta Oseas, expresa una ternura que nos pone ante un Dios que es todo cercanía: «Con cuerdas humanas los atraía, con lazos de amor, y era para ellos como los que alzan a un niño contra su mejilla» (Os 11, 4).

Se invita, pues, al discípulo a que supere vivencias negativas y perciba de verdad el amor de Dios y les llene de seguridad: «Ante todo quiero decirle a cada uno la primera verdad: «Dios te ama». Si ya lo escuchaste no importa, te lo quiero recordar: Dios te ama. Nunca lo dudes, más allá de lo que te suceda en la vida. En cualquier circunstancia, eres infinitamente amado» (n. $\left.{ }^{0} 112\right)$.

Sigue comparando esa historia de amor con el amor de la madre y, citando a Is 49, 15 dice: «Aunque ella se olvidara, yo no te olvidaré». Con frecuencia, en lugar de intentar asemejarnos al Padre-Dios, presentamos y nos creamos una figura de un Dios terrible hasta el punto de que lo mejor es separarnos de Él. No hemos escuchado su palabra constante de amor, por esa razón muchos jóvenes no se acercan a Dios: piensan que es un ser temible y alejan de ellos a quien les parece que está constantemente vigilando para castigarlos en el momento en el infrinjan su ley; sin embargo, Dios nos ama tanto que no quiere vivir sin nosotros. Es su amor el que nos cuida, no le somos indiferentes, cada uno le importa.

\section{A Dios le importas}

Veamos lo que dice el Santo Padre al comienzo del número 115: «Para Él realmente eres valioso, no eres insignificante, le importas, porque eres obra de sus manos. Por eso te presta atención y te recuerda con cariño».

Ciertamente somos valiosos para Dios. Si no fuese así, ¿hubiera enviado a su Hijo para que nos mostrase el camino de salvación, haciéndose uno de nosotros y acercándose hasta compartir la vida del hombre? Quizás las personas humanas somos gente olvidadiza o no queremos verlo tal cual 
Él se nos quiere presentar. Ya en el Antiguo Testamento dice: ¿Hay un pueblo entre nosotros que tenga a sus dioses tan cercanos como lo está Yahveh con su pueblo? Nos ocurre que no estamos dispuestos a ponernos en sus manos, a dejar que Dios esté con nosotros. Es cierto que el hombre de hoy está más cerca de la duda, del no fiarse de nadie. Es tan grande el desengaño que hemos sufrido, nos frenan tantos problemas, casos tan dolorosos...

El hombre de hoy parece incapaz de creer en alguien, parece no poder fiarse de nadie. Son muchas las cosas que creíamos que estaban cimentadas en la justicia y en la honradez y nos decepcionan, nos sorprenden con sus contrarios... Y el hombre se siente tentado a creerse abandonado, solitario; siente miedo a compartir, a hacer a los demás partícipes de su vida a dar y promover la vida ${ }^{1}$.

\section{El Amor de Dios se escribe con mayúscula}

Quizás condicionados por nuestra manera de amar, por los intereses que, de forma más o menos intensa, se dan en nuestras relaciones con los demás, hemos proyectado esta debilidad en nuestro Dios. No hemos mirado ni contemplado el retrato que, ya el Antiguo Testamento, pero de una manera más profunda y clara en el Nuevo, nos da la Sagrada Escritura. Leer el libro del Éxodo como una obra de amor a Dios que acompaña a su Pueblo, un texto donde se va desarrollando paulatinamente la acción de la gracia y en el que se concreta lo que es un Dios Padre que quiere que sus hijos se le parezcan en el amor, la bondad, el respeto de unos para con otros, el compartir lo que se tiene... Existe una continua dedicación divina para que el pueblo elegido camine seguro por el incierto desierto, allá donde no hay caminos, donde se está llamado a hacer el propio camino (todo un símbolo de que Dios no condiciona), si bien siguiendo las señales que el Señor le pone para que no se desvíe hacia el abismo y la condena. Ese es el sentido que tienen los castigos (pedagógicos siempre) que Yahveh-Dios impone a ese pueblo "de dura cerviz», incapaz de descubrir el amor y el mimo que Dios pone en cada momento. Se trata de un amor «que no aplasta, que no margina, que no se calla, un amor que no humilla ni avasalla. Es el amor del Señor, un amor de todos los días, discreto y respetuoso, amor de libertad y para la libertad, amor que cura y que levanta. Es el amor del Señor que sabe más de levantadas que de caídas, de reconciliación que de prohibición, de dar una nueva oportunidad que de condenar, de futuro más que de pasado» (n. $\left.{ }^{\circ} 116\right)$.

1. C. M. Martini, Por los caminos del Señor, Santander 1997, 210. 
¡Qué importante es contemplar lo que el Papa nos dice de las cualidades del amor! Seguro que tiene en su corazón lo que el apóstol Pablo dice en 1 Cor 13, traducido al aquí y ahora. Dios es todopoderoso, pero su poder no lo utiliza ni para aplastar ni para marginar, tampoco para ocultar el abuso de los poderosos de este mundo. No sólo no quiere avasallar, sino que además tiende la mano para levantarnos cuando caemos, para animarnos cuando pasamos por una fase depresiva, para elevar nuestra moral cuando, decaídos, vemos el mundo cubierto por un enorme nubarrón oscuro que tapa la luz.

Hace años, cuando el mayo francés del 68, aparecieron pintadas con la frase «Prohibido, prohibir», al margen de una de ellas alguien había escrito «Pues no prohíbas». Cuantas veces nosotros prohibimos prohibir (lo que nosotros consideramos incuestionable) y también consideramos que Dios es el Gran Prohibidor y por esa razón muchos se alejan de Él, creen que les coarta la vida, que no puede ejercer su libre albedrío. Pero Dios sabe más de levantadas que de caídas, nos invita a la reconciliación, no le gusta ni la guerra ni el abuso del pobre sobre el débil, le encanta la colaboración entre las personas, el caminar unidos. Ante el pueblo que se ha alejado, tras reprocharle su mala conducta, para que sintamos su amor presencial por medio del profeta Oseas dice:

Pero yo la conquistaré de nuevo, la llevaré al desierto y allí le hablaré con ternura. Allí le devolveré sus viñas y transformaré su valle de Penas en entrada hacia la Esperanza. Ella me responderá allí, cantando con gozo, tal como en los días de su juventud, como en el día cuando la saqué de Egipto. En aquel día ella me llamará «mi esposo» en vez de «mi señor». Lo digo yo, el Señor. Israel, yo haré que olvides tus ídolos y que nunca más siquiera menciones sus nombres. En aquel tiempo yo haré un trato entre ti y los animales salvajes, las aves y las víboras, para que no sientan temor los unos de los otros. $Y$ también destruiré todas las armas y todas las guerras terminarán. Entonces todos podrán vivir tranquilos (Os 2, 14-23).

Todo es para bien: «Cuando te pide algo o cuando sencillamente permite esos desafíos que te presenta la vida, espera que le des un espacio para poder sacarte adelante, para promoverte, para madurarte. No le molesta que le expreses tus cuestionamientos, lo que le preocupa es que no le hables, que no te abras con sinceridad al diálogo con Él» (n. $\left.{ }^{\circ} 117\right)$.

Dios no te quiere mudo y alejado, te invita a que le muestres tus dificultades en el camino, tus fracasos, incluso aquello de lo que no estás convencido y, por ello, necesitas que su luz te lo aclare. Lo que Dios quiere es que sintamos su presencia como liberadora. La tarea del Hijo es llevarnos al Padre e introducirnos en la filiación. 
Hay que presentar un Dios que sea de verdad amable, deseable, cuya presencia dé seguridad y alegría, no miedo ni encogimiento. Jesús nos habla de un Dios paternal, un Dios en quien podemos confiar, que nos da la vida, que nos escucha y cuida de nosotros, un Dios que perdona nuestros pecados y se adelanta a nuestras necesidades ${ }^{2}$.

Esa es la actitud de Padre, no la de ser un Dios alejado del hombre, sino un Padre-Dios que quiere siempre lo mejor para sus hijos. Esos que Jesús, por su muerte y en su resurrección, le ganó para siempre. El débil hijo de Adán fortalecido con la presencia en su vida de quien es el mayor cuidador de la raza humana, que, a veces, se ve relegado por dioses que ni salvan, ni pueden hacerlo porque responden más al deseo de superar limitaciones o conseguir caprichos que a una perspectiva de vida plena. De todas formas, hemos de renovar nuestra imagen de Dios. Hemos de alejar de nosotros el temor a Dios que no es lo mismo que «el temor de Dios». Este último es la preocupación por no seguir el camino al que nos invita, el cuidado para serle fieles, lo cual indica seguridad en Él y fidelidad en el caminar, pero nunca tener miedo de que nos castigue, porque «el Hijo del hombre ha venido al mundo no para castigar y condenar, sino para salvarlos».

La imagen de Dios como un anciano bondadoso con barbas blancas sentado sobre las nubes ya no nos vale. La gente ya sabe que Dios no está en las nubes. Hay que pensar más bien en presentarlo como un ser espiritual que está dentro de nosotros. Dios es el amigo presente e invisible, el Ser Original que nos precede, que está en nuestro interior, en el origen de los que somos y hacemos, y nos sostiene con su amor ${ }^{3}$.

\section{CRIsto TE SALVA}

Dios ha dado su vida por ti en la cruz

«La segunda verdad es que Cristo, por amor, se entregó hasta el final para salvarte. Sus brazos abiertos en la cruz son el signo más precioso de un amigo capaz de llegar hasta el extremo: 'Él, que amó a los suyos que estaban en el mundo, los amó hasta el fin' (Jn 13, 1)» (n. $\left.{ }^{\circ} 118\right)$.

La experiencia del amor entregado de Jesús marca una dimensión nueva en el amor que Dios nos tiene. Podría haber hecho las cosas de otra manera, pero quiso enviar al Hijo para que con su sangre derramada nos situara entre la debilidad de la persona humana y el poder de Dios, resucitándole. Esta resurrección, que es el triunfo de la vida sobre la muerte,

2. F. Sebastián, Claridad y firmeza. Transmitir la fe hoy en España, Madrid 2019, 132.

3. Ibid., 132-133. 
no es un alarde de poder de Jesús, sino un signo profundo de amor del Padre mediante el Hijo que, tras compartir la vida de los hombres, eleva la dignidad de los mismos y los «prepara» para superar las limitaciones y debilidades, porque su sangre redentora y su resurrección ponen un horizonte renovado y renovador a la vida. Además, no es un perdón que se realice una sola vez, sino que siempre está con los brazos abiertos para volver a recibirnos todas las veces que, arrepentidos de nuestro pecado, acudamos humildemente ante Él.

Hay que nacer de nuevo y nacer como discípulos de Jesús. Viene bien recordar aquí las hermosas reflexiones de san Agustín cuando habla de los deseos como camino de la gracia en nuestro corazón. Somos hombres sin grandes deseos, nos contentamos con poco. Y Dios no puede entrar en un corazón sin deseos 4 .

Es muy importante poner nuestro horizonte en términos de gran exigencia, porque si nuestra finalidad en la vida, los objetivos que nos proponemos, están a ras de suelo, sin afán de superar lo que son las verdaderas dificultades, en una conformidad de robot, que solo se mueve si le pulsan el resorte, caeremos en una vida anodina, puramente de instinto, y conforme vaya rebajándose nuestro nivel de deseo se irá cerrando las perspectiva de la novedad de vida que es Jesús. Sólo tenemos que mirar a nuestro alrededor para comprobar que la falta de exigencia en la vida, la falta de horizontes que den ilusión, una descafeinada esperanza y un amor que se concreta en poder satisfacer mis instintos, ha dado con el ser humano en tierra, pero no pisando la realidad, sino pisoteándose a sí mismo y su dignidad de hijo de Dios. Necesitamos que Cristo siga rescatándonos de nuestra caída al vacío: «Ese Cristo que nos salvó en la cruz de nuestros pecados, con ese mismo poder de su entrega total sigue salvándonos y rescatándonos hoy. [...] Y si pecas y te alejas, Él vuelve a levantarte con el poder de su cruz (n. $\left.{ }^{\circ} 119\right)$.

Este es el seguro de vida: Dios nunca te abandona, constantemente está llamando a tu puerta y, si eres joven, con más insistencia, porque lo único que desea es que seas feliz y descubras esa felicidad que sólo con el corazón henchido se percibe y que es, a su vez, contagiosa. No se trata de que uno se convenza intelectualmente, ni le atrapen los razonamientos, las palabras, sino de tener experiencia de que Dios es una presencia real en mi vida y me busca porque me ama, ya que Dios no es que solamente ame, es que Él es el Amor. Y este amor de Dios está por encima de tus pecados: 
«El amor del Señor es más grande que todas nuestras contradicciones, que todas nuestras fragilidades y que todas nuestras pequeñeces. Pero es precisamente a través de nuestras contradicciones, fragilidades y pequeñeces como Él quiere escribir esta historia de amor» $\left(n{ }^{\circ} 120\right)$.

Una de las realidades que nos pueden alejar de Dios son nuestras contradicciones, o sea, el decir una cosa y hacer lo contrario, el no saber desmontar la trama de perversión que existe en nosotros o que pulula a nuestro alrededor. Podríamos decir que la contradicción, el error, el hacer aquello que no deseas, es una constante en cada joven e incluso en cada persona adulta. Parece como si lo morboso ejerciera un extraño atractivo en cada uno de nosotros. Nos hace esto pensar en que la maldad está tan dentro que nos es imposible el perdón. Sin embargo, Dios, que es PADRE, conoce nuestra debilidad y pequeñez, y no por eso deja de amarnos. Es más, deja las noventa y nueve ovejas, que están seguras en el redil, y va a buscar la que se ha perdido, y se alegra cuando la encuentra, y quiere hacer partícipe de esa alegría a todos. Hay una fiesta en el cielo por cada pecador que se convierte.

Quiere el Papa dejarnos bien claro lo que significa esta realidad del amor gratuito y constante. «Su perdón y su salvación no son algo que hemos comprado, o que tengamos que adquirir con nuestras obras o con nuestros esfuerzos. Él nos perdona y nos libera gratis. Su entrega en la cruz es algo tan grande que nosotros no podemos ni debemos pagarlo, sólo tenemos que recibirlo con inmensa gratitud y con la alegría de ser tan amados antes de que pudiéramos imaginarlo: 'Él nos amó primero' (1 Jn 4, 19)» (n. $\left.{ }^{\circ} 121\right)$.

Si de verdad fuésemos capaces de captar algo de lo que esto significa, nuestra actuación cambiaría y nos haría cada vez más humanos.

\section{Tu vida es un tesoro, vale toda la sangre de Cristo}

"Jóvenes amados por el Señor, ¡cuánto valen ustedes si han sido redimidos por la sangre preciosa de Cristo! Jóvenes queridos, ustedes ¡no tienen precio! ¡No son piezas de subasta! Por favor, no se dejen comprar, no se dejen seducir, no se dejen esclavizar por las colonizaciones ideológicas que nos meten ideas en la cabeza y al final nos volvemos esclavos, dependientes, fracasados en la vida. Ustedes no tienen precio: deben repetirlo siempre: no estoy en una subasta, no tengo precio. ¡Soy libre, soy libre! Enamórense de esta libertad, que es la que ofrece Jesús» (n. $\left.{ }^{\circ} 122\right)$.

En nuestra miopía, en ese caminar temerosos de si no llegamos a conseguir lo que materialmente anhelamos, de tener esa seguridad que nos permita una vida confortable, no acabamos de percibir lo que significa ese 
valor. El Santo Padre nos advierte: no sois objetos de subasta, no podéis ser comprados, no os dejéis esclavizar, no perdáis la libertad que Jesús os da. Si nos ponemos a mirar nuestros sistemas educativos, nuestra dependencia de multitud de aparatos, las adicciones que nos impiden decidir sin estar condicionados, con las secuelas de sentirnos maniatados o, peor aún, no darnos cuenta de que estamos atados de pies y manos y que cada vez ese nudo es más fuerte y difícil de desatar. Jesús sí valora tu vida y sigue ofreciéndote lo mejor, en cualquier modalidad de respuesta vocacional: lai$\mathrm{co}$, sacerdote, religioso, son solamente modalidades de la única respuesta a la vida, la que el Padre te ofrece para tu felicidad.

\section{El sacrificio es constructivo. Mira al crucificado y déjate salvar por Él}

A continuación, el Papa nos invita a que nos dejemos acoger por los brazos abiertos de Jesús. Además de una realidad es también el símbolo de la acogida y el perdón. Para mí, el retrato más fiel que Jesús hace del Padre está reflejado en la parábola del Padre misericordioso (o del «hijo pródigo»). El hijo le pide que le dé la herencia (en griego, ton bion, cuyo significado es que le deje hacer con su vida lo que le venga en gana). El Padre ha dejado al hijo menor en libertad, pero está siempre esperando su regreso, no quiere que le pille desprevenido la vuelta del hijo que ha dilapidado su herencia, su vida; por eso, cuando lo ve venir, sale corriendo a su encuentro y lo recibe con todos los honores, hasta mata el ternero cebado. Está tan feliz por haberlo recuperado que antes que en él, piensa en que el hijo haya recuperado su vida y está de nuevo en camino de la felicidad en la casa paterna. Las reflexiones del hijo no parecen, en principio, estar motivadas por el amor al padre, sino porque en la casa del padre hasta el más sencillo de los obreros está bien; con la celebración del banquete el hijo recupera su dignidad (el calzado, la túnica). Seguro que el hijo ha reafirmado que solo junto al Padre se es feliz, y lejos de la casa paterna viene la degeneración, el caer hasta ser tenido por menos que un cerdo (animal maldito y prohibido para los judíos), ni siquiera puede compartir con el la mesa, la experiencia es decisiva para que se haya decidido a volver y atiende la voz en su interior: Déjate salvar, es lo único que Dios-Padre te pide, para eso ha enviado al mundo al Hijo.

«Mira los brazos abiertos de Cristo crucificado, déjate salvar una y otra vez. $Y$ cuando te acerques a confesar tus pecados, cree firmemente en su misericordia que te libera de la culpa. Contempla su sangre derramada con tanto cariño y déjate purificar por ella. Así podrás renacer, juna y otra vez!» (n. $\left.{ }^{0} 123\right)$. 


\section{CRISTO VIVE, HA RESUCITADO}

Cristo no es un personaje de la historia, como pueden serlo Napoleón, David, Marcos, san Pablo, Nerón y otros muchos. Esto no significa que no sea un personaje histórico, porque sí que estuvo con nosotros, caminó por este mundo y pasó haciendo el bien. También es verdad que fue crucificado, pero lo importante es que Cristo es el que promueve y hace progresar nuestra historia, porque Él vive, ha resucitado, volvió a la vida e hizo un breve camino aquí en la tierra con sus discípulos tras la resurrección. Los discípulos se resistieron a creer que todo había ocurrido tal como que les había dicho, pero se rindieron a la verdad experimentada: Cristo ha resucitado.

A estas verdades, el Papa recuerda una tercera, inseparable de las dos anteriores: «jÉl vive! Hay que volver a recordarlo con frecuencia, porque corremos el riesgo de tomar a Jesucristo sólo como un buen ejemplo del pasado, como un recuerdo, como alguien que nos salvó hace dos mil años. Eso no nos serviría de nada, nos dejaría iguales, eso no nos liberaría. El que nos llena con su gracia, el que nos libera, el que nos transforma, el que nos sana y nos consuela es alguien que vive. Es Cristo resucitado, lleno de vitalidad sobrenatural, vestido de infinita luz. Por eso decía san Pablo: «Si Cristo no resucitó vana es vuestra fe $(1$ Cor 15,17$) »\left(n .{ }^{\circ} 124\right)$.

Ciertamente Dios no es un Dios de muertos, sino de vivos, y la expresión sublime de esta realidad es que nos muestra el camino de la vida a través del compartir del Hijo y señalarnos la vida que no se acaba. Presente en nuestra vida, vive y nos anima a vivir. Nos quiere, por esa razón, llenos de ánimo, de ilusión, de esperanza, confiados en su Palabra y trasmisores de esperanza. Madre Teresa de Calcuta decía que si los cristianos mostramos el rostro como de quienes están siempre llorando, porque las cosas no salen como cada uno pretende, sólo damos pena y somos personajes de una tragedia sin horizonte. Solamente mostrando la alegría de vivir la fe llamaremos la atención, «mirad como ríen los cristianos, tienen una alegría que se contagia», sería una versión actualizada de ese «mirad como se aman los cristianos» que tantas conversiones produjo. Pero esa realidad tiene que brotar de lo más hondo de nuestra vida, porque:

Si has encontrado a Jesús superficialmente, por tradición o por costumbre, si no tienes una idea clara de él, si no lo conoces con fuerza, como salvador, como señor de tu existencia, como vida del hombre, como solución de los problemas humanos, como respuesta a tus interrogantes, como pan que alimenta tu vida, como medicina para tus sufrimientos y tus heridas, como el que satisface tus deseos, entonces no puedes ser su testigo ${ }^{5}$.

\section{C. M. Martini, Por los caminos del Señor, 263.}


Que está presente en la vida de cada uno y que hace su camino con nosotros es una realidad que experimentamos en momentos de paz y silencio, también en situaciones de necesidad. Está presente en tu vida, camina contigo: «Si él vive, entonces sí podrá estar presente en tu vida, en cada momento, para llenarlo de luz. Así no habrá nunca más soledad ni abandono. Aunque todos se vayan él estará, tal como lo prometió: 'Yo estoy con ustedes todos los días, hasta el fin del mundo' (Mt 28, 20). Él lo llena todo con su presencia invisible, y donde vayas te estará esperando. Porque él no sólo vino, sino que viene y seguirá viniendo cada día para invitarte a caminar hacia un horizonte siempre nuevo» ( $\left.\mathrm{n}{ }^{\circ} 125\right)$.

El encuentro con Cristo es un precioso tesoro, el más importante que se deposita en nuestras manos. si bien Dios, desde el principio de la creación, puso al hombre al frente de lo que había creado, se fio de él y le entregó todas las cosas, el mayor tesoro está por venir con la encarnación del Hijo, su caminar entre nosotros, su entrega y su resurrección. Pero este tesoro, que llevamos en vasos de barro, no está destinado a que nos quedemos con él, porque tanta gracia, tan enorme riqueza no puede sino ser comunicada a todos y cada uno de los hermanos. Esto nos impulsa a darlo a conocer: «Si alcanzas a valorar con el corazón la belleza de este anuncio y te dejas encontrar por el Señor; si te dejas amar y salvar por él; si entras en amistad con él y empiezas a conversar con Cristo vivo sobre las cosas concretas de tu vida, esa será la gran experiencia, esa será la experiencia fundamental que sostendrá tu vida cristiana. Esa es también la experiencia que podrás comunicar a otros jóvenes. Porque 'no se comienza a ser cristiano por una decisión ética o una gran idea, sino por el encuentro con un acontecimiento, con una Persona, que da un nuevo horizonte a la vida y, con ello, una orientación decisiva'» (n. $\left.{ }^{\circ} 129\right)$.

Es fundamental que se realice ese encuentro; solamente la presencia experimentada por cada uno de su amistad es y contagia el querer apuntarse a ese camino.

\section{EL ESPÍRITU DA VIDA}

\section{El protagonista es el Espíritu Santo, no tú}

El Espíritu de la verdad guía hacia la plenitud de verdad que es Cristo, el Hijo de Dios hecho carne, Palabra definitiva del encuentro dialogal de Dios y el hombre. Él es el que va haciendo pedagogía con cada uno para que vayamos descubriendo y entendiendo, en la verdad experiencial, quien es Jesús, cómo nos muestra el camino y el conocimiento del Padre y de qué manera actúa en nosotros. 
Su labor la realiza promoviendo la conversión de la vida humana a Cristo, este es el fin de toda la acción del Espíritu Santo. En cada proceso de discernimiento (tan importante para acertar en la dirección de nuestra vida) es la luz del Espíritu la que nos hace descubrir los momentos importantes de la decisión. El joven que quiera seguir el camino con Jesús ha de ser una persona abierta, porque el ser humano, en el fondo, es un ser cerrado, desconfiado, continuamente pendiente de defender su exiguo patrimonio personal, falto de confianza en sí mismo ${ }^{6}$.

Por este motivo se siente arrojado en las manos de la nada, en los brazos de su ambición y de su egoísmo; prendido por esas realidades, se siente incapaz de progresar. Cuando nos damos cuenta de la limitación, entonces dejamos que actúe en nosotros el Espíritu. Pablo nos dice que «hace el mal que no quiere y no el bien que desearía». También las personas vemos el bien y desearíamos que ese fuese el tono de nuestra vida, pero nos sentimos débiles y, sin la fuerza del Espíritu no realizamos lo que queremos. «Video meliora, proboque, deteriora sequor» ". No se trata de ver lo que es bueno y aplaudirlo, sino de seguir su camino.

\section{CONCLUSIÓN}

Es importante que recordemos lo dicho hasta aquí y lo hagamos con las palabras del Papa en su Exhortación: «En estas tres verdades-Dios te ama, Cristo es tu salvador, Él vive- aparece el Padre Dios y aparece Jesús. Dónde están el Padre y Jesucristo, también está el Espíritu Santo. Es él quien está detrás, es él quien prepara y abre los corazones para que reciban ese anuncio, es él quien mantiene viva esa experiencia de salvación, es él quien te ayudará a crecer en esa alegría si lo dejas actuar. El Espíritu Santo llena el corazón de Cristo resucitado y desde allí se derrama en tu vida como un manantial. Y cuando lo recibes, el Espíritu Santo te hace entrar cada vez más en el corazón de Cristo para que te llenes siempre más de su amor, de su luz y de su fuerza» (n. $\left.{ }^{\circ} 130\right)$.

Nos anima a que acudamos a él cada día y nos pongamos bajo la fuerza de su amor, para que a través del joven lo contagie en el ambiente de vida que se genera a su alrededor. Pero la fuerza es del Espíritu, no tuya. Acude a él cada día y pídele que contagies el amor de Dios a tu alrededor: «Invoca cada día al Espíritu Santo, para que renueve constantemente en ti la experiencia del gran anuncio» $\left(n .{ }^{\circ} 131\right)$.

6. C. M. Martini, Por los caminos del Señor, 200.

7. «Veo el camino del bien y lo aplaudo, pero sigo el camino del mal» (traducción ad sensum). 
Vivir bajo la fuerza que da el Espíritu implica caminar, ir hacia delante, no quedarse congelado en un tiempo concreto, en el «cualquier tiempo pasado fue mejor», sino abrirse al horizonte de renovación constante que te ofrece la dinámica de la vida. Sólo se es joven de verdad sabiendo caminar a lo largo de la historia, renovando las coordenadas de la misma bajo la luz, siempre original y nueva, del Espíritu. Cuando leo el evangelio y veo que Jesús rara vez está quieto esperando que acudan a él, la gente le sigue, va caminando y él se detiene para atenderlos, regalándoles su palabra y preocupándose de que no les falte lo necesario, como sucede en la multiplicación de los panes y los peces. No podemos querer una comunidad eclesial anclada en el pasado, porque la salvación es dinamismo y se ofrece a todos y cada uno de los humanos de hoy y de mañana. El Espíritu es fuego que purifica y fuerza que anima a caminar. «Él es el manantial de la mejor juventud» ( $\left.n .^{\circ} 133\right)$.

«Enamórate y no le dejarás, no le dejes y te enamorarás»

«¿Buscas pasión? Como dice ese bello poema: ¡Enamórate! (o déjate enamorar), porque nada puede importar más que encontrar a Dios. Es decir, enamorarse de Él de una manera definitiva y absoluta. Aquello de lo que te enamoras atrapa tu imaginación, y acaba por ir dejando su huella en todo. Será lo que decida qué es lo que te saca de la cama en la mañana, qué haces con tus atardeceres, en qué empleas tus fines de semana, lo que lees, lo que conoces, lo que rompe tu corazón y lo que te sobrecoge de alegría y gratitud. ¡Enamórate! ¡Permanece en el amor! Todo será de otra manera. Este amor a Dios que toma con pasión toda la vida es posible gracias al Espíritu Santo, porque 'el amor de Dios ha sido derramado en nuestros corazones con el Espíritu Santo que nos ha sido dado' (Rom 5, 5)» (n. $\left.{ }^{\circ} 132\right)$.

Pongamos nuestro interés en transmitir amor, en introducirnos en el amor de Dios, eso es enamorarse: compartir amor y que este nos ayude a transformar la vida. Esa es una de las misiones más importantes del joven de hoy. Recordemos siempre estas cuatro verdades: 1) Dios es Amor: te ama, le importas. 2) Este amor está por encima de tus pecados, Él te regala la salvación. 3) Cristo está vivo, ha resucitado. 4) Es Espíritu y da vida. El mal no tiene la última palabra.

Así el joven de hoy también se sentirá acompañado, amado y valorado. 